Trauma Surgery \& Acute Care Open

\title{
Building the future for national trauma research
}

\author{
Michelle A Price (1) $, 1,2$ Rosemary A Kozar, ${ }^{3}$ Eileen M Bulger, ${ }^{4}$ Gregory J Jurkovich, ${ }^{5}$ The \\ Coalition for National Trauma Research Scientific Advisory Committee
}

'National Trauma Insitute, San Antonio, Texas, USA 2Department of Surgery, UT Health - San Antonio, San Antonio, TX, United States ${ }^{3}$ R Adams Cowley Shock Trauma Center, Baltimore, Maryland, USA

${ }^{4}$ Department of Surgery, University of Washington, Seattle, Washington, USA ${ }^{5}$ Department of Surgery, University of California Davis School of Medicine, Sacramento, California, USA

Correspondence to Dr Michelle A Price, National Trauma Insitute, San Antonio, TX 78230,USA; Michelle@ NatTrauma.org

Received 27 November 2019 Accepted 5 December 2019

\section{(c) Author(s) (or their} employer(s)) 2020. Re-use permitted under CC BY-NC. No commercial re-use. See rights and permissions. Published by BMJ.

To cite: Price MA, A Kozar $R$, Bulger EM, et al. Trauma Surg Acute Care Open 2020:5:e000421.

\section{SUMMARY}

This paper describes the current funding, infrastructure growth and future state of trauma research. It also introduces a group of review articles generated from The Future of Trauma Research: Innovations in Research Methodology conference hosted by the American College of Surgeons Committee on Trauma in July 2019.

\section{INTRODUCTION}

Traumatic injury is a major public health problem across the globe. In the USA, trauma is the leading cause of death from ages 1 to 46 years and accounts for more years of potential life lost before age 75 than any other medical problem. ${ }^{1}$ The estimated cost of traumatic injury to our society in 2013 was $\$ 671$ billion per year. $^{2}{ }^{3}$ Despite the well-known burden of disease imposed by injury, funding for trauma-related research remains profoundly deficient. Glass et al recently reported that only 3.7\% of all National Institutes of Health (NIH) grants were trauma-related, representing $2.9 \%$ of the total NIH extramural budget. ${ }^{4}$ A study by Moses et al evaluated NIH funding relative to the burden of disease, as measured by Disability-adjusted Life Years, and reported that injury was the least funded of 27 disease conditions. ${ }^{5}$

The issue of insufficient funding for trauma research is not new. A 1966 report published by the National Research Council, Accidental Death and Disability, first highlighted the lack of funding and called for the development of a National Institute at the NIH focused on trauma and emergency care. ${ }^{6}$ In the ensuing five decades, the lack of a federal home for trauma research has continued. A report from the National Academies of Sciences, Engineering and Medicine (NASEM) in 2016 titled, A National Trauma Care System: Integrating Military and Civilian Trauma Systems to Achieve Zero Preventable Deaths after Injury, further highlighted the gaps in research funding and the need for a coordinated approach. ${ }^{1}$ Recommendation 7 from this report is as follows: To strengthen trauma research and ensure that the resources available for this research are commensurate with the importance of injury and the potential for improvements in patient outcomes, the White House should issue an executive order mandating the establishment of a National Trauma Research Action Plan requiring a resourced, coordinated, joint approach to trauma care research across the US Department of Defense (DOD), US Department of Health and Human services (National Institutes of Health, Agency for Healthcare Research and Quality, Centers for Disease Control and Prevention, US Food and
Drug Administration, Patient-centered Outcomes Research institute, the US Department of Transportation, the US Department of Veterans Affairs, and others (academic institutions, professional societies, foundations)) (page 361). To date, there has been no federal response to the NASEM report's recommendations.

\section{THE COALITION FOR NATIONAL TRAUMA RESEARCH}

In response to the shortfalls in federal research funding, professional societies and trauma community stakeholders have struggled to find ways to support academic efforts in trauma research. Coalition for National Trauma Research (CNTR) was established in 2014 in an effort to bring together the major academic professional organizations focused on injury to develop strategies to enhance trauma research coordination and funding. ${ }^{7}$ CNTR's mission is to enhance trauma research in the USA by advocating for sustainable funding commensurate with the burden of disease, coordinating research efforts across professional organizations which span the continuum of injury care, and strengthening the infrastructure for multicenter investigation. The current CNTR members include representatives from these professional societies: American Association for the Surgery of Trauma, American College of Surgeons Committee on Trauma (ACS COT), Eastern Association for the Surgery of Trauma, Western Trauma Association, and the National Trauma Institute (NTI). The NTI is a multispecialty stakeholder organization with the mission to generate funding and provide infrastructure to sustain trauma research. ${ }^{8}$ NTI manages CNTR research projects as well as the National Trauma Research Repository (NTRR). ${ }^{9}$ The NTRR is a Department of Defense-funded, cloud-based data repository that supports national trauma research efforts (DoD Contract \# W81XWH-15-2-0089). The repository provides trauma researchers with a means to securely share research data for secondary analyses as required by funders and journals.

\section{DEVELOPING A NATIONAL TRAUMA RESEARCH ACTION PLAN}

To date, CNTR has successfully advocated for an additional \$30 million in trauma research funding through the Department of Defense. However, this investment addresses only a small fraction of the burden of traumatic injury on society. Considering the $2013 \$ 671$ billion cost of trauma in the USA, and given inflation of $10.22 \%$ since that time, to fund research commensurate with such a burden would require $\$ 740$ billion in today's dollars. ${ }^{3} 10$ 
Table 1 NIH funding for various research and conditions related to injury (in millions)

\begin{tabular}{|c|c|c|c|c|c|c|}
\hline Research area & FY2015 actual & FY2016 actual & FY2017 actual & FY2018 actual & FY2019 estimate & FY2020 estimate \\
\hline Emergency care & $\$ 122$ & $\$ 129$ & $\$ 139$ & $\$ 146$ & $\$ 156$ & $\$ 135$ \\
\hline Homicide and legal intervention & $\$ 1$ & $\$ 1$ & $\$ 1$ & $\$ 2$ & $\$ 2$ & $\$ 2$ \\
\hline Injury (total) accidents/adverse & $\$ 399$ & $\$ 447$ & $\$ 496$ & $\$ 639$ & $\$ 725$ & $\$ 609$ \\
\hline Suicide & $\$ 46$ & $\$ 52$ & $\$ 68$ & $\$ 96$ & $\$ 117$ & $\$ 96$ \\
\hline Suicide prevention & $\$ 24$ & $\$ 33$ & $\$ 35$ & $\$ 51$ & $\$ 69$ & $\$ 55$ \\
\hline Violence research & $\$ 107$ & $\$ 111$ & $\$ 115$ & $\$ 131$ & $\$ 140$ & $\$ 122$ \\
\hline Total (in millions) & $\$ 699$ & $\$ 773$ & $\$ 854$ & $\$ 1065$ & $\$ 1209$ & $\$ 1019$ \\
\hline
\end{tabular}

In reality, the NIH reports its annual funding for injury-related research (table 1) from 2015 through 2020 is less than $1 \%$ of the disease burden. To make matters worse, the agency's reporting likely includes duplication (across categories) and funding for other non-trauma emergency conditions. ${ }^{11}$

To achieve the goal of research funding at a level commensurate with societal burden requires the full commitment of the federal government, including the creation of a Trauma Institute within the NIH. Until such time as a Trauma Institute is established, CNTR has made an effort to implement NASEM report recommendations, and has received grant funding from the DOD to develop a National Trauma Research Action Plan (NTRAP). The proposal's three aims are to (1) perform a gap analysis of military and civilian trauma research to identify priorities across the continuum of care; (2) define optimal metrics to assess longterm functional outcomes in injured patients following hospital discharge; and (3) identify research regulatory barriers, develop best practices for investigators, and collaborate with federal entities to define optimal endpoints for clinical research. While this project will not attempt to quantify the exact amount of research funding necessary, the results will serve as a roadmap for research funding priorities.

The NTRAP proposal was funded in 2018 and is underway (DOD Contract \# W81XWH-18-CO179). Aim 1 will provide a comprehensive research agenda through the work of stakeholder panels that are currently engaging in a Delphi process to identify research gaps in 11 focus areas: prehospital care \& mass casualty triage; acute resuscitation, evaluation, \& imaging; post-admission critical care; neurotrauma; orthopedic trauma; burns \& reconstructive surgery; long-term functional outcomes $\&$ rehabilitation; geriatric trauma, pediatric trauma, injury prevention, and trauma systems $\&$ informatics. In addition to CNTR, 18 professional societies provided representatives to the panels comprising more than 400 experts and stakeholders. Aim 2 was initiated in conjunction with a Patient Reported Outcomes Consensus Conference hosted by the ACS COT in January 2019, which brought together experts from across the globe to review the current evidence for long-term outcome assessment. Systematic literature reviews are now underway, which will be followed by Delphi panels to build consensus regarding the optimal patient reported outcomes after injury. Aim 3 will engage trauma researchers, federal regulatory agencies, and experts in clinical trial design to address human subjects protection barriers and meaningful clinical outcomes for trials. In all, NTRAP will provide a road map for future investigators and support for ongoing advocacy for sustainable federal research funding.

\section{DEVELOPING CNTR INFRASTRUCTURE FOR MULTICENTER INVESTIGATIONS}

In 2019, to address the goal of improving the infrastructure for multicenter clinical trials in trauma, CNTR formed a Scientific Advisory Council (SAC) that includes representatives appointed from each member organization. This council is charged with identifying opportunities to leverage the resources of all the CNTR organizations to support grant submissions addressing key clinical questions in trauma care. For example, one option is to leverage the data collection infrastructure of the ACS Trauma Quality Improvement Program (TQIP) to conduct pragmatic clinical trials or design implementation studies for best practices. To facilitate the work of the SAC, CNTR held a 1-day educational symposium focused on novel and innovative clinical trial methodologies applicable to care of the injured patient hosted by the ACS COT in July 2019. The meeting was co-chaired by Drs Eileen Bulger, current Chair of the American College of Surgeons Committee on Trauma and member of the CNTR Executive Committee, and Avery Nathens, Medical Director for Trauma Quality Programs at the ACS. The symposium, The Future of Trauma Research: Innovations in Research Methodology included both experienced and emerging surgical researchers, all nominated by the CNTR organizations. Representatives from the American College of Emergency Physicians and the Pediatric Trauma Society also participated.

National experts in each topic area were solicited to present (table 2). Dr Avery Nathens discussed the potential for better utilizing the ACS TQIP as infrastructure to conduct clinical trials; Dr Carly Parry, a senior advisor on Healthcare Delivery and Disparities Research for the Patient-Centered Outcomes Research Institute (PCORI), offered strategies for obtaining research funding through PCORI, particularly for comparative effectiveness research; and Dr David Chambers, Deputy Director for Implementation Science at the National Cancer Institute, shared the NIH perspective on methods of implementation science. Additional speakers included experts on adaptive trial design, platform trials, pragmatic clinical trials, and de-implementation studies. The group also heard from Dr Robert Fowler on the lessons learnt from the highly productive Canadian Critical Care Clinical Trials Group.

This day-long seminar made it clear hat there is opportunity to apply these innovative approaches to trauma research. The following day, members of CNTR SAC, chaired by Dr Rosemary Kozar, met to discuss ways to best design and implement these novel approaches to advance the field. The goals of the SAC are to identify innovative, pragmatic research methods appropriate for trauma research, build a clinical research network, and determine study priorities that use TQIP data infrastructure. The SAC is developing projects for prospective clinical research/ clinical trials that will be attractive and relevant to federal agencies. These proposals will be based on research frameworks that 
Table 2 The Future of Trauma Research: Innovations in Research Methodology Agenda

\begin{tabular}{|c|c|}
\hline Topic & Speaker \\
\hline $\begin{array}{l}\text { Methods of Implementation Science: NIH } \\
\text { Perspective }\end{array}$ & David Chambers, DPhil \\
\hline Studying Implementation and De-Implementation & Christian Helfrich, MPH, PhD \\
\hline Transitional Care Network (PICORI) & Carly Parry, PhD \\
\hline Adaptive Clinical Trial Design and Platform Trials & Robert Silbergleit,MD \\
\hline Pragmatic Clinical Trials & Paul Karanicolas MD, PhD \\
\hline Pragmatic Trials in PTSD & Douglas Zatzick, MD \\
\hline $\begin{array}{l}\text { Integrating Health Economics into Clinical } \\
\text { Research }\end{array}$ & Ricardo Pietrobon MD, PhD \\
\hline $\begin{array}{l}\text { Secrets to Success from the Canadian Critical } \\
\text { Care Trials Group }\end{array}$ & Robert Fowler, MDCM, MSc \\
\hline
\end{tabular}

NIH, National Institutes of Health; PCORI, Patient-Centered Outcomes Research Institute.

will eventually support the implementation of the NTRAP as described above. Anticipated benefits from this cross-society collaboration include the following: (1) Increased collaboration across professional society-sponsored multi-site studies to maximize funding and reduce duplication; (2) A coordinated network approach to apply for funding and conduct multi-site studies; (3) Harmonization of research data through the adoption of common data elements; and (4) Increased secondary analyses through data sharing and research repositories. As it evolves, CNTR SAC will provide resources and guidance to support investigators to develop project proposals and leverage the CNTR infrastructure to support application submissions for multicenter trials.

\section{THE FUTURE}

This series is a CNTR initiative to promote sustainable, highquality research that further advances the care of injured patients at a funding level commensurate with the burden of disease in the USA. The companion articles in this publication aim to inform the trauma research community on innovative study designs, implementation research, and patient-centered research opportunities. In the manuscript titled, "Alternative Clinical Trial Designs," Dr Harvin et al describe the limitations of traditional clinical trials and how types of alternative trial designs can mitigate those limitations. Additionally, the authors discuss how Bayesian methods of inference may provide more knowledge to trauma researchers compared with traditional, frequentist statistical methods. In "Dissemination, implementation, and de-implementation: The trauma perspective," Dr Ho and her co-authors describe the principles of implementation science and propose their wider use in trauma care. The manuscript reviews implementation, dissemination, and de-implementation, as well as research frameworks, study design, and related research funding opportunities. Finally, in "Patient-centered outcomes research and the injured patient: A summary of application," Dr Godat et al review the basics of patient-centered outcomes research, priorities for funding from PCORI, resources for collaboration around patient-centered outcomes research, and a unique career development opportunity for early career trauma surgeons to develop a skillset in patient-centered outcomes research.

CNTR is committed to advancing the care of the injured patient through impactful trauma research. CNTR seeks to broaden the engagement of other medical specialty societies who share a significant focus on injury research. We believe that to successfully achieve the goal of a dedicated NIH Institute for
Trauma research with sustainable funding commensurate with the burden of traumatic injury on our society, we need to be maximally inclusive and united in our advocacy efforts. As Dr Ronald M. Stewart, Founding Chairman of the NTI has stated, "It has been proven in many other major disease categories that research works-it establishes the evidence that improves outcomes and saves lives. Accelerated progress in trauma care requires significant and sustained funding of trauma research." 12

Acknowledgements The authors greatly appreciate the ongoing financial support of The Coalition for National Trauma Research Scientific Advisory Committee (CNTR SAC) from the following organizations: American Association for the Surgery of Trauma (AAST), American College of Surgeons Committee on Trauma (ACS-COT), Eastern Association of the Surgery of Trauma (EAST), National Trauma Institute (NTI), and Western Trauma Association (WTA). The Future of Trauma Research: Innovations in Research Methodology Conference was made possible through funding by the American College of Surgeons. This work is supported in part by the US Army Medical Research and Materiel Command under Contract No. W81XWH18-C-0179. The views, opinions and/or findings contained in this report are those of the author(s) and should not be construed as an official Department of the Army position, policy or decision unless so designated by other documentation.

Collaborators Members of the Coalition for National Trauma Research Scientific Advisory Committee: Saman Arbabi, MD FACS, Eileen M. Bulger, MD FACS (Department of Surgery, University of Washington); Mitchell J. Cohen, MD FACS (Department of Surgery, University of Colorado); Todd W. Costantini, MD FACS (Department of Surgery, UC San Diego School of Medicine): Marie M. Crandall, MD, MPH FACS (Department of Surgery, University of Florida College of Medicine Jacksonville); Rochelle A. Dicker, MD FACS (Departments of Surgery and Anesthesia, UCLA Geffen School of Medicine); Elliott R. Haut, MD, PhD FACS (Departments of Surgery, Anesthesiology and Critical Care Medicine and Emergency Medicine, The Johns Hopkins University School of Medicine; The Armstrong Institute for Patient Safety and Quality, Johns Hopkins Medicine; Department of Health Policy and Management, The Johns Hopkins Bloomberg School of Public Health); Bellal Joseph, MD FACS (Department of Surgery, University of Arizona); Rosemary A. Kozar, MD, PhD FACS (Department of Surgery, University of Maryland); Ajai K. Malhotra, MD FACS (Department of Surgery, University of Vermont); Avery B. Nathens, MD, PhD FRCS, FACS (Department of Surgery, University of Toronto); Raminder Nirula, MD, MPH FACS (Department of Surgery, University of Utah); Michelle A. Price, PhD, MEd (National Trauma Institute, UT Health - San Antonio); Jason W. Smith, MD FACS (Department of Surgery, University of Louisville); Deborah M. Stein, MD, MPH FACS FCCM (Department of Surgery, University of California - San Francisco); Ben L. Zarzaur, MD, MPH FACS (Department of Surgery, University of Wisconsin School of Medicine and Public Health).

Contributors All of the authors participated in the conceptualization of this manuscript. MAP, RAK, EMB, and GJJ wrote and revised the manuscript. All authors reviewed and approved the manuscript.

Funding This work is supported in part by the US Army Medical Research and Materiel Command under Contract No. W8XWH-18-C-0179.

Competing interests None declared.

Patient consent for publication Not required.

Provenance and peer review Not commissioned; internally peer reviewed.

Open access This is an open access article distributed in accordance with the Creative Commons Attribution Non Commercial (CC BY-NC 4.0) license, which permits others to distribute, remix, adapt, build upon this work non-commercially, and license their derivative works on different terms, provided the original work is properly cited, appropriate credit is given, any changes made indicated, and the use is non-commercial. See: http://creativecommons.org/licenses/by-nc/4.0/.

ORCID iD

Michelle A Price http://orcid.org/0000-0001-6402-7956

\section{REFERENCES}

1 National Academies of Sciences Engineering and Medicine. A National Trauma Care System: Integrating Military and Civilian Trauma Systems to Achieve Zero Preventable Deaths After Injury. Washington, DC, USA: National Academies Press, 2016.

2 Florence C, Simon T, Haegerich T, Luo F, Zhou C. Estimated Lifetime Medical and WorkLoss Costs of Fatal Injuries--United States, 2013. MMWR Morb Mortal Wkly Rep 2015:64:1074-7.

3 Centers for Disease Control and Prevention and National Center for Injury Prevention and Control. Costs of Injury in the U.S. 2017. https://www.cdc.gov/injury/wisqars/cost/ index.html (August 1, 2017 [cited 2019 October 30, 2019]). 
4 Glass N, Riccardi J, arber NI, Bonne SL, Livingston DH. Disproportionately low funding for trauma research by the National Institutes of health: a call for a national Institute of trauma. J Trauma Acute Care Surg 2019.

5 Moses H, Matheson DHM, Cairns-Smith S, George BP, Palisch C, Dorsey ER. The anatomy of medical research: US and international comparisons. JAMA 2015:313:174-89.

6 Institute of Medicine, Committee on Trauma and Committee on Shock, and Division of Medical Sciences. Accidental death and disability: the neglected disease of modern society. Washington, D. C: National Academy of Sciences, National Research Council, 1966.

7 Coimbra R, Kozar RA, Smith JW, Zarzaur BL, Hauser CJ, Moore FA, Bailey JA, Valadka $A$, Jurkovich $\mathrm{GJ}$, Jenkins $\mathrm{DH}$, et al. The coalition for national trauma research supports the call for a national trauma research action plan. J Trauma Acute Care Surg 2017;82:637-45.

8 Price MA, Beilman GJ, Fabian TC, Hoyt DB, Jurkovich GJ, Knudson MM, MacKenzie EJ Marshall VS, Overton KE, Peitzman AB, et al. The National trauma Institute: lessons learned in the funding and conduct of 16 trauma research studies. J Trauma Acute Care Surg 2016;81:548-54.

9 Price MA, Bixby PJ, Phillips MJ, Beilman GJ, Bulger EM, Davis MR, McAuliffe MJ, Rasmussen TE, Salinas J, Smith SL, et al. Launch of the National trauma research Repository coincides with new data sharing requirements. Trauma Surg Acute Care Open 2018;3:e000193.

10 U.S. Official Inflation Data and Alioth Finance. \$671B in 2013 converted to 2019 Inflation Calculator. 2019. http://www.in2013dollars.com/us/inflation/2013?amount= 671 (October 30, 2019).

11 National Institutes of Health and Research Portfolio Online Reporting Tools (RePORT). Estimates of funding for various research, condition, and disease categories (RCDC). 2019. https://report.nih.gov/categorical_spending.aspx (April 19, 2019).

12 National Trauma Institute. Who we are. 2019. https://www.nattrauma.org/who-weare/ 